\title{
Sarcopenia Associated with Chronic Obstructive Pulmonary Disease
}

\author{
Sang Hun Kim', Myung Jun Shin', Yong Beom Shin', Ki Uk Kim² \\ ${ }^{1}$ Department of Rehabilitation Medicine, Biomedical Research Institute, Pusan National University Hospital, Pusan National University \\ School of Medicine, Busan; \\ ${ }^{2}$ Department of Internal Medicine, Pusan National University School of Medicine, Busan, Korea
}

\author{
Corresponding author \\ Myung Jun Shin \\ Department of Rehabilitation Medicine, \\ Biomedical Research Institute, Pusan National \\ University Hospital, Pusan National University \\ School of Medicine, 179 Gudeok-ro, Seo-gu, \\ Busan 49241, Korea \\ Tel: +82-51-240-7485 \\ Fax: +82-51-247-7485 \\ E-mail: drshinmj@gmail.com
}

Received: February 11, 2019

Revised: April 3, 2019

Accepted: April 20, 2019
Sarcopenia is frequently associated with chronic diseases such as chronic obstructive pulmonary disease (COPD) and cancer. COPD, which is characterized by an irreversible airflow limitation, exacerbates respiratory distress as the disease progresses. The prevalence of sarcopenia in stable COPD was reported to be $15 \%$ to $25 \%$ in previous foreign studies and $25 \%$ in a Korean study. As the amount of activity decreases, muscle mass decreases and eventually oxygen cannot be used effectively, resulting in a vicious cycle of deterioration of exercise capacity. Deconditioning due to decreased activity is a major cause of limb muscle dysfunction in patients with COPD. In these patients, the factors that decrease muscle strength and endurance include chronic inflammation, oxidative stress, inactivity, hypoxemia, hormone abnormality, deficits of nutrients such as protein and vitamin $\mathrm{D}$, and the use of systemic corticosteroid. Therefore, treatment and management should either inhibit this process or should be directed toward supplementing the deficiency, such as with exercise, nutritional support, and medications and supplements. The relationship between sarcopenia and COPD is increasingly being reported, with some overlap in clinical features and treatments. We are fascinated to be able to diagnose 2 diseases through similar physical performance tests and to improve both diseases using the same treatment such as exercise. Therefore, this review summarizes the clinical relevance and integrative management of the 2 diseases.

Key Words: Chronic obstructive · Exercise therapy · Pulmonary disease · Rehabilitation · Sarcopenia - Vitamin D

\section{INTRODUCTION}

Societies are aging all over the world, and medical attention has focused on changes in body composition during the aging process. As aging progresses, lean body mass decreases and fat percentage increases.[1] These changes in metabolism cause the loss of muscle mass and lower functional status. In 1989, Rosenberg [2] first expressed medical interest in the changes in muscles that accompany aging and suggested the use of the term "sarcopenia" for aging-associated loss of muscle. Since then, sarcopenia has become a more comprehensive term that includes the concept of loss of muscle function as well as the amount of muscle. [3] If there is difficulty in moving, a gradual decline in health status, or a recent history of falls, an unintended weight loss of $5 \%$ or more may suggest sarcopenia.

\section{Mineral Research}

This is an Open Access article distributed under the terms of the Creative Commons Attribution Non-Commercial License (http://creativecommons.org/licenses/by-nc/4.0/) which permits unrestricted non-commercial use, distribution, and reproduction in any medium, provided the original work is properly cited.

\section{KSBMR}


[4] Sarcopenia is frequently associated with chronic diseases such as type 2 diabetes mellitus, chronic heart failure, chronic obstructive pulmonary disease (COPD), chronic kidney disease, rheumatoid arthritis, and cancer. The cutoff value for muscle mass is slightly different depending on the working group, and the prevalence of sarcopenia (low muscle mass) in South Korea is reported to be quite different depending on which value is used. Although systematic domestic data are still lacking, 9.3\% of elderly men and $0.2 \%$ to $22.1 \%$ of elderly women are considered to have sarcopenia using the appendicular skeletal muscle mass (ASM)/height ${ }^{2}\left(\mathrm{ht}^{2}\right)$ index in the data from the Korean National Health and Nutrition Examination Survey (KNHANES).[5,6] According to the KNHANES, $13.4 \%$ of the population aged 40 years or older has COPD.[7] A relationship between sarcopenia and COPD is increasingly reported, and there is some overlap in clinical features and treatments. It is fascinating to be able to diagnose 2 diseases through similar physical performance tests and to improve both diseases through the same treatment, such as exercise. Therefore, this review summarizes the clinical relevance and integrative management of the 2 diseases.

\section{DIAGNOSIS OF SARCOPENIA}

Many diagnostic methods have been proposed at various conferences, but recently more detailed diagnostic criteria have been suggested. The European Working Group on Sarcopenia in Older People (EWGSOP) presented a European consensus on the definition and diagnosis of sarcopenia in 2010, which was updated in 2018 by EWGSOP2. EWGSOP2 used low muscle mass and muscle function (muscle strength and physical performance) as criteria for diagnosing sarcopenia. In EWGSOP2, low muscle strength is defined as the first parameter of sarcopenia, and diagnosis is confirmed by the presence of decreased muscle mass (quantity and quality). Physical performance was previous-

Table 1. Operational definition of sarcopenia by European Working Group on Sarcopenia in Older People 2

\begin{tabular}{lccc}
\hline & $\begin{array}{c}\text { Muscle } \\
\text { strength }\end{array}$ & $\begin{array}{c}\text { Muscle quan- } \\
\text { tity/quality }\end{array}$ & $\begin{array}{c}\text { Physical per- } \\
\text { formance }\end{array}$ \\
\hline Probable sarcopenia & $\downarrow$ & & \\
Sarcopenia & $\downarrow$ & $\downarrow$ & $\downarrow$ \\
Severe sarcopenia & $\downarrow$ & $\downarrow$ & $\downarrow$ \\
\hline
\end{tabular}

ly a core parameter for diagnosis, but it is now proposed as a parameter to categorize the severity of sarcopenia in the revised definition (Table 1).[1,8]

In EWGSOP2, it was confirmed that the previous cut-off values for muscle mass are difficult to memorize. For this reason, the working group decided to sacrifice precision and use cutoff points that are close to references to make them easy to remember. The Asian Working Group for Sarcopenia (AWGS) is similar to the EWGSOP, but its criteria provide other clinical guidelines. For Asian people, SMI is $7.0 \mathrm{~kg} / \mathrm{m}^{2}$ for men and $5.4 \mathrm{~kg} / \mathrm{m}^{2}$ for women when using dual energy X-ray absorptiometry (DXA), and $7.0 \mathrm{~kg} / \mathrm{m}^{2}$ for men and $5.7 \mathrm{~kg} / \mathrm{m}^{2}$ for women when using bioimpedence analysis (BIA). In principle, the AWGS follows the diagnostic approach of the EWGSOP and revises and adds cut points in some areas from the Asian perspective. The sarcopenia project of the Foundation for the National Institutes of Health $(\mathrm{FNIH})$ is designed to determine muscle strength levels associated with mobility disability and then determine the

Table 2. Cut-off values for sarcopenia by EWGSOP2, AWGS, and FNIH sarcopenia project

\begin{tabular}{|c|c|c|c|}
\hline & Muscle mass & Muscle strength & $\begin{array}{c}\text { Physical } \\
\text { performance }\end{array}$ \\
\hline EWGSOP2 & $\begin{array}{l}\text { ASM } / \mathrm{ht}^{2 \mathrm{al}} \\
<7.0 \mathrm{~kg} / \mathrm{m}^{2} \text { in men } \\
<6.0 \mathrm{~kg} / \mathrm{m}^{2} \text { in } \\
\text { women }\end{array}$ & $\begin{array}{l}\text { Grip strength } \\
<27 \mathrm{~kg} \text { in men } \\
<16 \mathrm{~kg} \text { in women }\end{array}$ & $\begin{array}{l}\text { SPPB } \leq 8 \\
\text { Gait speed } \leq 0.8 \\
\quad \mathrm{~m} / \mathrm{sec} \\
\text { TUG } \geq 20 \text { sec } \\
400 \mathrm{~m} \text { walk test } \\
\geq 6 \text { min for } \\
\text { completion or } \\
\text { non-completion }\end{array}$ \\
\hline AWGS & $\begin{array}{l}\text { DXA }{ }^{\text {b) }}, A S M / h^{2} \\
\leq 7.0 \mathrm{~kg} / \mathrm{m}^{2} \text { in men } \\
\leq 5.4 \mathrm{~kg} / \mathrm{m}^{2} \text { in } \\
\text { women } \\
\mathrm{BIA}^{\mathrm{bl}}, \mathrm{SMl} / \mathrm{ht}^{2} \\
\leq 7.0 \mathrm{~kg} / \mathrm{m}^{2} \text { in men } \\
\leq 5.7 \mathrm{~kg} / \mathrm{m}^{2} \text { in } \\
\text { women }\end{array}$ & $\begin{array}{l}\text { Grip strength } \\
<26 \mathrm{~kg} \text { in men } \\
<18 \mathrm{~kg} \text { in women }\end{array}$ & $\begin{array}{l}\text { Gait speed }<0.8 \\
\mathrm{~m} / \mathrm{sec}\end{array}$ \\
\hline $\begin{array}{l}\text { FNIH sar- } \\
\text { copenia } \\
\text { project }\end{array}$ & $\begin{array}{l}\text { ASM/BMI } \\
<0.789 \text { in men } \\
<0.512 \text { in women }\end{array}$ & $\begin{array}{l}\text { Grip strength } \\
<26 \mathrm{~kg} \text { in men } \\
<16 \mathrm{~kg} \text { in women }\end{array}$ & $\begin{array}{l}\text { Gait speed }<0.8 \\
\mathrm{~m} / \mathrm{sec}\end{array}$ \\
\hline
\end{tabular}

a)DXA is advised in clinical practice, and DXA, BIA, computed tomography or magnetic resonance imaging in research studies. ${ }^{\text {bl Defined as }-2}$ standard deviations less than the mean of that of healthy young adults of the same sex and ethnic background.

EWGSOP2, European Working Group on Sarcopenia in Older People 2; AWGS, Asian Working Group for Sarcopenia; FNIH, Foundation for the National Institutes of Health; ASM, appendicular skeletal muscle mass; $\mathrm{Ht}$, height; DXA, dual energy X-ray absorptiometry; BIA, bioimpedence analysis; SMI, skeletal muscle mass index; BMI, body mass index; SPPB, short physical performance battery; TUG, Timed Up \& Go. 
level of muscle mass that would identify clinically appropriate muscle weakness. Therefore, the FNIH sarcopenia project recommends the ASM/body mass index (BMI) ratio, which is an indicator of muscle mass, divided by the BMI of ASM.[9] The cutoff values established by the international working groups are summarized in Table 2 .

\section{CLINICAL SIGNIFICANCE OF SARCOPENIA}

Sarcopenia is associated with loss of mobility, falls, osteoporosis, poor quality of life (QOL) due to fracture, hospitalization, and death.[10] In addition, the loss of muscle mass and function lead to decreases in physical activity and energy consumption, resulting in an increase in body weight.[11] As a result, pulmonary function is reduced, and cardiovascular and metabolic diseases are more likely to occur. A study of the elderly in their 70 s to 90 s revealed that mortality increased by 1.9 times for every $1 \mathrm{~kg} / \mathrm{m}^{2}$ reduction of lean body mass for 2 years.[12] In Korean studies, 500 elderly patients over 65 years of age were followed up for 6 years. The mortality rate for those with sarcopenia was 2.99 times higher in men and 3.22 times higher in women than that of the normal group, based on the EWGSOP criteria.[13]

\section{CLINICAL FEATURES OF COPD}

COPD is now the fourth leading cause of death worldwide. In 2012, more than 3 million people worldwide died of COPD, accounting for $6 \%$ of all deaths.[14] COPD is an important disease in public health because it can be prevented and treated. Forced expiratory volume in one second $\left(\mathrm{FEV}_{1}\right)$, which can be confirmed by pulmonary function tests, is important for the evaluation of COPD patients. Worsening dyspnea reduces the patient's physical performance. As a result, life satisfaction is lowered and anxiety and depression may occur.[15] COPD characterized by irreversible airflow limitation exacerbates respiratory distress as the disease progresses. As the amount of activity decreases, muscle mass decreases and eventually oxygen cannot be used effectively, resulting in a vicious cycle of deterioration of exercise capacity (Fig. 1).[16] In the BODE index (BMI, FEV 1 , dyspnea measured by the modified Medical Research Council, 6-min walk distance) designed for COPD mortality prediction, exercise capacity and muscle mass

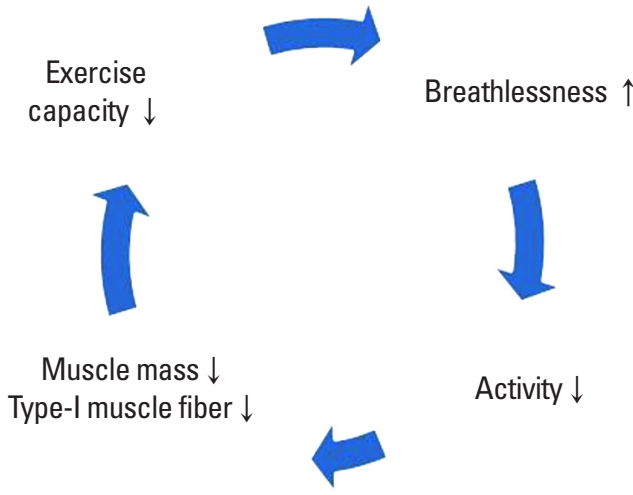

Fig. 1. Vicious cycle of inactivity in chronic obstructive pulmonary disease.

are the main prognostic factors.[17] In other words, the clinical significance of physical activity in COPD is as important as that of medical treatment.

\section{MUSCLE DYSFUNCTION IN COPD}

Deconditioning due to decreased activity is a major cause of limb muscle dysfunction. In chronic diseases such as COPD, however, problems such as inflammation, oxidative stress, malnutrition, and hypoxemia may also cause skeletal muscle dysfunction.[18] The rate of malnutrition in patients with COPD increases with the severity of the disease, up to $30 \%$ in the Global Initiative for Chronic Obstructive Lung Disease (GOLD) stage 4.[19] In addition, changes in body composition are reported in up to $35 \%$ of cases in which the fat free mass (FFM) index (FFMI) is significantly lower than normal.[20] Even if the BMI is normal, the evaluation of body composition is important because the FFMI is often low. One study revealed that low FFMI correlates strongly with mortality in COPD patients with normal weight. [21] In patients with COPD, atrophy of the legs, especially the thigh muscles, was dominant over the whole body.[22] In severe COPD, it was confirmed that muscle fiber shifted from type I to type IIx, unlike in the normal aging process. [23] These abnormal fiber shifts led to inefficiencies that result in high oxygen demand at submaximal workloads. [24] Systemic oxidative stress was found to be associated with endurance of the quadriceps muscle in patients with severe COPD.[25] More oxidative stress in the limb muscles and poor function of the quadriceps muscle were reported in patients with hypoxemia.[26] Quadriceps muscle strength was reported to be $20 \%$ to $30 \%$ lower in patients with COPD 
than in normal people.[27] Decreased muscle endurance of the quadriceps in patients with COPD has been reported. $[25,26,28]$ Muscle endurance was also significantly reduced with hypoxemia as well as muscle strength.[26] Many COPD patients complain of leg muscle fatigue before dyspnea, and exercise is stopped. Various studies have been conducted using subjective or objective methods. Objective methods include measuring muscle twitch after magnetic stimulation,[29] or measuring the median frequency of surface electromyography.[30] Systemic inflammation in patients with COPD has recently been identified as a cause of other complications such as cachexia and osteoporosis. [31-33] Among them, chronic inflammation in stable COPD patients is suspected as the cause of sarcopenia, and several studies are underway. Byun et al.[32] reported that high levels of high-sensitivity tumor necrosis factor-a (hsTNF-a), an inflammatory biomarker, were significant predictors of the presence of sarcopenia (odds ratio, 1.99; $95 \%$ confidence interval, 1.04-3.81) in 80 stable COPD patients.

Acute exacerbation of COPD is a condition best avoided during the course of the disease, but it is common. If acute exacerbation occurs at any time and the patient is admitted to the hospital, deterioration of systemic function including limb muscle strength can easily occur. Quadriceps muscle weakness after acute exacerbation of COPD is frequently reported, and weakened muscles recover 3 months or more after discharge.[33] Limb muscle dysfunction during acute exacerbations may be due to various factors such as systemic inflammation, malnutrition, and steroid use, as well as physical inactivity. A decreased mid-thigh muscle cross-sectional area and decreased quadriceps muscle strength contribute to increased mortality in COPD.[34] In addition, mortality was almost doubled when FFMI was less than $16 \mathrm{~kg} / \mathrm{m}^{2}$ in men and less than $15 \mathrm{~kg} / \mathrm{m}^{2}$ in women. [21] In conclusion, muscle strength, endurance, and muscle mass of the thigh are clinically important in COPD patients. For diagnosis of sarcopenia, muscle strength is measured by grip strength, not knee extensor strength, as a consensus made to simplify the diagnosis. In other words, evaluation of limb muscle dysfunction in COPD is not completely consistent with the diagnosis of sarcopenia, but it can be expected that there will be high correlation between the 2 diseases.

\section{PREVALENCE OF SARCOPENIA IN COPD}

The prevalence of sarcopenia in stable COPD was reported to be $15 \%$ to $25 \%$ in previous foreign studies and $25 \%$ in a Korean study.[32,35,36] Sarcopenia prevalence was inversely related to the modified Medical Research Council Dyspnea Scale and BODE index scores, and a higher prevalence was observed with lower 6-min walking distance.[32] The prevalence of sarcopenia in COPD patients is higher than that in normal elderly people. Therefore, COPD may be one cause of sarcopenia.[37] Physical frailty is defined as "a medical syndrome that increases the vulnerability of an individual to dependence and death due to a reduction in physical strength, endurance, and physiological function due to various causes." The frailty prevalence rate in stable COPD diagnosed with the fatigue, resistance, ambulation, illnesses, and loss of weight scale was $6.6 \%, 50 \%$ of which was diagnosed as sarcopenia. The prevalence of sarcopenia in the non-frail COPD group was 22.2\%.[38] Frailty, sarcopenia and COPD tend to overlap some in some of their features and disease course.

\section{MANAGEMENT OF SARCOPENIA IN COPD}

In patients with COPD, the factors that decrease muscle strength and endurance include chronic inflammation, oxidative stress, inactivity, hypoxemia, hormone abnormality, deficits of nutrients including protein and vitamin $D$, and the use of systemic corticosteroid. Therefore, treatment and management should either inhibit this process or go in the direction of supplementing the deficient elements. Some approaches are summarized below.

\section{Exercise}

Pulmonary rehabilitation (PR) in patients with COPD has already been proven beneficial with high-quality evidence. [39] In other words, PR improves the exercise capacity of the patient and improves dyspnea and QOL. PR is a multidisciplinary integrated treatment program that includes exercise, education, behavior change, and nutritional therapy. Exercise refers to a planned and repetitive activity for a specific purpose over a certain period of time, with a definition different from that of physical activity. Exercise is also one of the most effective ways to improve sarcopenia. The EWGSOP noted that exercise with a primary goal of im- 
proving physical performance, strength, and muscle mass is needed for sarcopenia treatment.[1]

Exercise in sarcopenia is largely composed of resistance exercise, aerobic exercise, and balance and flexibility exercises. Intensive resistance training by elderly patients effectively increases muscle function and mass.[40] However, the elderly should perform gradual overload exercise at the intensity that they can perform. Prevention of musculoskeletal injuries is also important, and the primary purpose of exercise in sarcopenia is to improve muscle function and strength. 1 repetition maximum (RM; maximum weight that can be lifted at one time, for example, 3 RM can be repeated 3 times, but that weight cannot be lifted 4 times) is recommended, but it is somewhat burdensome for the elderly.[41] We recommend a weight repetition method that regards the weight that can be lifted 2 to 3 times as $80 \%$ of $1 \mathrm{RM}$. Generally, it is appropriate to start with $50 \%$ to $60 \%$ of $1 \mathrm{RM}$ and to repeat it 12 to 15 times without causing too much muscle fatigue. If muscle strength is improved, then 1 RM should be reevaluated to gradually increase exercise intensity and gradually increase the frequency to 1 to 3 sets a day. It has been confirmed that gradual resistance exercise restores the muscle strength of the thigh muscles in frail elderly people.[42] Although it has been shown previously that the proximal thigh of COPD patients does not necessarily have a linear correlation with sarcopenia, the function of the thigh muscle plays an important role in daily activities such as walking or sitting. It is predictable that weakness of the thigh muscle eventually causes physical inactivity.

Balance exercise should be performed in the elderly, as a decreased sense of balance will make inactivity worse, and even simple aerobic exercise such as walking will be difficult to perform. A systematic review suggests that resistance exercise alone has limitations in improving postural control,[43] and balance exercise must be included to improve postural control.[44]

$\mathrm{VO}_{2 \text { max }}$, the maximum amount of oxygen that can be consumed during exercise, is the most useful indicator of cardiovascular endurance. In the elderly, it starts at $40 \%$ to $50 \%$ of $\mathrm{VO}_{2 \max }$ and gradually increases to $60 \%$ to $70 \%$. In COPD patients or elderly people with sarcopenia, however, it is not easy to perform a proper exercise test. In this case, exercise intensity can be determined using the 6 min walk test (6MWT), rating of perceived exertion (RPE), and heart
Table 3. Modified Borg Scale

\begin{tabular}{ll}
\hline Scale & \multicolumn{1}{c}{ Symptom } \\
\hline 0 & No breathlessness at all \\
0.5 & Very, very slight (just noticeable) \\
1 & Very slight \\
2 & Slight breathlessness \\
3 & Moderate \\
4 & Somewhat severe \\
5 & Severe breathlessness \\
6 & \\
7 & Very severe breathlessness \\
8 & \\
9 & Very, very severe (almost maximal) \\
10 & Maximal \\
\hline
\end{tabular}

rate.[45] For example, an average speed of $3.0 \mathrm{~km} / \mathrm{hr}$ can be calculated when walking $300 \mathrm{~m}$ for $6 \mathrm{~min}$, and a speed of $1.8 \mathrm{~km} / \mathrm{hr}$ can be determined if $60 \%$ exercise intensity is prescribed. The modified 0 to 10 Borg scale [46] is commonly used as a subjective evaluation method, and RPE is classified as 0 (inactivity) to 10 (maximal dyspnea), with recommended intensity of 3 to 5 (Table 3). Alternatively, the maximum heart rate method can be used to simply multiply the desired exercise intensity by subtracting the age of the patient from 220, which is effective when using a fitness tracker that can monitor HR in a home exercise program. Aerobic exercise should be performed at least 3 times a week and is recommended for 20 to $60 \mathrm{~min}$. Most studies have shown that at least 6 to 8 weeks of treatment should be effective in improving COPD symptoms and improving cardiovascular endurance.[47] Although the most accurate aerobic exercise regimen can be prescribed with a treadmill, the recumbent cycle is often used because of the high risk of falling when the sense of balance is decreased in the elderly. However, since the cycle uses many leg muscles, aerobic exercise may not reach the appropriate intensity. Therefore, it is important to choose the exercise method according to the situation.

Although COPD PR and exercise therapy in sarcopenia can be considered to overlap in many ways (Fig. 2), there are some additional considerations in patients with COPD. First, respiratory function is lowered compared to elderly people with sarcopenia. In particular, attention should be paid to the possibility of exercise-induced desaturation (EID) in patients with severe and very severe COPD with FEV 1 below 50\%.[48] Uncorrected $\mathrm{SpO}_{2}$ below $90 \%$ is an 


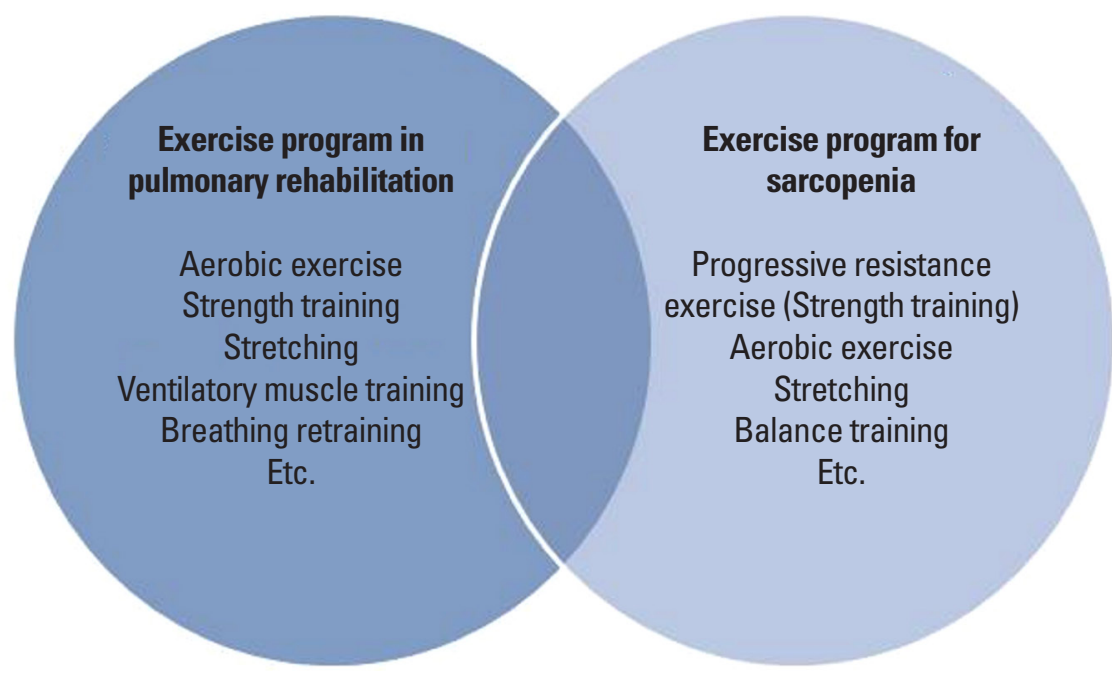

Fig. 2. Exercise program for chronic obstructive pulmonary disease and sarcopenia.

indication to terminate aerobic exercise, so if EID is identified, adequate oxygenation should be performed during exercise. Also, aerobic exercise by the elderly in the domestic environment is likely to be performed mainly outdoors. Recently, air pollution has become an issue, and fine particles can acutely exacerbate lung disease in some patients. [49] Depending on the concentration of fine particles, elderly people with lung disease may need to be told to exercise indoors.

\section{Nutritional support}

Malnutrition not only increases the risk of weight loss and disease but also affects sarcopenia. Protein is only used as an energy source if it is supplied with insufficient caloric intake. Therefore, sufficient nutritional supply and additional protein supply should be combined. According to the KNHANES (2014), $45.4 \%$ of elderly people under 75 years of age and $65.9 \%$ of elderly people over 75 years of age have protein intakes below recommended levels.[50] In most previous epidemiological studies, protein intake and muscle mass were positively correlated. In the Health $A B C$ study, 2,066 elderly people were classified according to their protein intake, with less muscle loss in the $1.2 \mathrm{~g} / \mathrm{kg}$ group than in the $0.8 \mathrm{~g} / \mathrm{kg}$ group.[51] In some clinical trials, it has been reported that FFM increases and leg strength improves when various types of amino acids are supplied during exercise training.[52-54] However, the effect of protein alone was limited.[55] The PROT-AGE study group recommended a protein supply of 1.0 to $1.2 \mathrm{~g} / \mathrm{kg}$ for healthy elderly people and 1.2 to $1.5 \mathrm{~g} / \mathrm{kg}$ for elderly people with chronic or acute disease.[56] The amino acid leucine plays an important role in the process of protein catabolism. Whey protein is recommended because it has the highest leucine content. Studies comparing animal and plant proteins have also reported a positive correlation with muscle mass and animal protein intake alone.[51] An adequate protein intake for protein synthesis is $30 \mathrm{~g}$ or more of animal protein per serving.

Malnutrition may be common when the severity of COPD is high. Significant improvements in mid-arm muscle circumference, FFMI, 6MWT, respiratory muscle strength, and overall health-related QOL have been reported with nutritional supplementation in malnourished patients with COPD.[55] In summary, patients with COPD and sarcopenia should first be checked for malnutrition, provided adequate nutritional support, and supplied with additional forms of protein.

\section{Medications}

Some medicines and supplements currently available in clinical practice may be useful for patients with sarcopenia and COPD. Vitamin D is thought to play an important role in muscle metabolism, and it was recently reported that vitamin $D$ plays a role in skeletal muscle mass and muscle strength. When vitamin D was deficient, atrophy of type II muscle fiber was confirmed.[57] Type II muscle fiber is involved in preventing falls by fast-twitching, so vitamin $D$ supplementation can eventually lead to a reduction in fall 
risk. It was also reported that muscle performance was improved when the 25 -hydroxy-vitamin $\mathrm{D}$ concentration was more than $60 \mathrm{nmol} / \mathrm{L}$.[58]

Beta-hydroxy- $\beta$-methylbutyrate (HMB) is a metabolite of leucine and is often used as a nutritional supplement during muscle training. $\mathrm{HMB}$ increases protein synthesis through protective and anti-catabolic effects. It also stabilizes muscle cell membranes and weakens proteolytic pathways. This process can contribute to a reduction of sarcopenia. Several studies have reported the effects of HMB in reducing myalgia, lowering blood markers of musculoskeletal dissemination, increasing FFM, and improving various physical performance indicators.[59] Wu et al.[60] reported that HMB supplementation was effective in maintaining muscle mass in the elderly through a meta-analysis of seven randomized controlled trials of healthy elderly people or cancer patients aged 65 years or older. In addition, in chronic diseases including COPD, HMB was effective in preventing muscle loss, and it was reported that the usual dose of $3 \mathrm{~g} /$ day HMB was effective with no definite side effects.[61]

Sarcopenia is accompanied by a decreased sensitivity to insulin and steroid hormones with aging, and various studies based on the development of such hormone analogues are under way. Selective Androgen Receptor Modulator has recently been shown to be effective in the prevention and treatment of muscle wasting in clinical trials in cancer patients,[62] and clinical trials are underway for other diseases such as COPD. In addition, metformin, a diabetes drug, is undergoing further studies at the animal testing level to confirm a muscle strengthening effect.[63]

\section{CONCLUSIONS}

The market is expected to expand rapidly, as a disease code (the International Classification of Diseases, Tenth Revision, Clinical Modification code, M62.84) for sarcopenia was granted in the United States in October 2016. As a result, further research on an international scale will be conducted. Already, the European Union's innovative medicine initiative has selected the development of drugs for sarcopenia as a major health topic. In other words, sarcopenia can be expected to have a status equivalent to that of the current osteoporosis market. The diagnosis and treatment of COPD is already systematized. In addition to vaccination and smoking cessation for the prevention and treatment of COPD, the PR has also gradually expanded in South Korea. In conclusion, if physicians are interested in COPD PR, it is possible to evaluate, prevent, and treat sarcopenia easily. In COPD patients, sarcopenia can be diagnosed through tests such as the grip test, DXA or BIA, and gait speed. Standardization of the evaluation guideline will facilitate investigation of the prevalence of sarcopenia in domestic COPD patients and enable effective exercise to be prescribed for the treatment of patients with sarcopenia with COPD.

\section{DECLARATIONS}

\section{Acknowledgments}

This work was supported by clinical research grant from Pusan National University Hospital in 2019.

\section{Ethics approval and consent to participate Not applicable.}

\section{Conflict of interest}

No potential conflict of interest relevant to this article was reported.

\section{ORCID}

Sang Hun Kim http://orcid.org/0000-0003-4849-5228

Myung Jun Shin http://orcid.org/0000-0003-4010-0383

Yong Beom Shin http://orcid.org/0000-0001-5026-1696

Ki Uk Kim http://orcid.org/0000-0002-0745-0675

\section{REFERENCES}

1. Cruz-Jentoft AJ, Baeyens JP, Bauer JM, et al. Sarcopenia: European consensus on definition and diagnosis: Report of the European Working Group on Sarcopenia in Older People. Age Ageing 2010;39:412-23.

2. Rosenberg IH. Sarcopenia: origins and clinical relevance. J Nutr 1997;127:990s-1s.

3. Roubenoff R. Sarcopenia: effects on body composition and function. J Gerontol A Biol Sci Med Sci 2003;58:1012-7.

4. Fielding RA, Vellas B, Evans WJ, et al. Sarcopenia: an undiagnosed condition in older adults. Current consensus definition: prevalence, etiology, and consequences. International working group on sarcopenia. J Am Med Dir Assoc 2011;12:249-56.

5. Kwon HJ, Ha YC, Park HM. Prevalence of sarcopenia in the 
Korean woman based on the Korean National Health and Nutritional Examination Surveys. J Bone Metab 2016;23: 23-6.

6. Kim KM, Jang HC, Lim S. Differences among skeletal muscle mass indices derived from height-, weight-, and body mass index-adjusted models in assessing sarcopenia. Korean J Intern Med 2016;31:643-50.

7. Yoo KH, Kim YS, Sheen SS, et al. Prevalence of chronic obstructive pulmonary disease in Korea: the fourth Korean National Health and Nutrition Examination Survey, 2008. Respirology 2011;16:659-65.

8. Cruz-Jentoft AJ, Bahat G, Bauer J, et al. Sarcopenia: revised European consensus on definition and diagnosis. Age Ageing 2019;48:16-31.

9. Studenski SA, Peters KW, Alley DE, et al. The FNIH sarcopenia project: rationale, study description, conference recommendations, and final estimates. J Gerontol A Biol Sci Med Sci 2014;69:547-58.

10. Visser M, Schaap LA. Consequences of sarcopenia. Clin Geriatr Med 2011;27:387-99.

11. Choi KM. Sarcopenia and sarcopenic obesity. Endocrinol Metab (Seoul) 2013;28:86-9.

12. Roubenoff R, Parise H, Payette HA, et al. Cytokines, insulinlike growth factor 1 , sarcopenia, and mortality in very old community-dwelling men and women: the Framingham Heart Study. Am J Med 2003;115:429-35.

13. Lim S, Kim JH, Yoon JW, et al. Sarcopenic obesity: prevalence and association with metabolic syndrome in the Korean Longitudinal Study on Health and Aging (KLoSHA). Diabetes Care 2010;33:1652-4.

14. American Lung Association. Trends in COPD (Chronic Bronchitis and Emphysema): Morbidity and mortality. 2013 [cited by 2016 Nov 23]. Available from: https://www.lung. org/assets/documents/research/copd-trend-report.pdf

15. Spruit MA, Singh SJ, Garvey C, et al. An official American Thoracic Society/European Respiratory Society statement: key concepts and advances in pulmonary rehabilitation. Am J Respir Crit Care Med 2013;188:e13-64.

16. Garvey C, Fullwood MD, Rigler J. Pulmonary rehabilitation exercise prescription in chronic obstructive lung disease: US survey and review of guidelines and clinical practices. J Cardiopulm Rehabil Prev 2013;33:314-22.

17. Celli BR, Cote CG, Marin JM, et al. The body-mass index, airflow obstruction, dyspnea, and exercise capacity index in chronic obstructive pulmonary disease. N Engl J Med
2004;350:1005-12.

18. Maltais F, Decramer M, Casaburi R, et al. An official American Thoracic Society/European Respiratory Society statement: update on limb muscle dysfunction in chronic obstructive pulmonary disease. Am J Respir Crit Care Med 2014;189:e15-62.

19. Vestbo J, Prescott E, Almdal T, et al. Body mass, fat-free body mass, and prognosis in patients with chronic obstructive pulmonary disease from a random population sample: findings from the Copenhagen City Heart Study. Am J Respir Crit Care Med 2006;173:79-83.

20. Coronell C, Orozco-Levi M, Gea J. COPD and body weight in a Mediterranean population. Clin Nutr 2002;21:437; author reply -8 .

21. Schols AM, Broekhuizen R, Weling-Scheepers CA, et al. Body composition and mortality in chronic obstructive pulmonary disease. Am J Clin Nutr 2005;82:53-9.

22. Bernard S, LeBlanc $P$, Whittom F, et al. Peripheral muscle weakness in patients with chronic obstructive pulmonary disease. Am J Respir Crit Care Med 1998;158:629-34.

23. Gosker HR, van Mameren H, van Dijk PJ, et al. Skeletal muscle fibre-type shifting and metabolic profile in patients with chronic obstructive pulmonary disease. Eur Respir J 2002;19:617-25.

24. Richardson RS, Sheldon J, Poole DC, et al. Evidence of skeletal muscle metabolic reserve during whole body exercise in patients with chronic obstructive pulmonary disease. Am J Respir Crit Care Med 1999;159:881-5.

25. Koechlin C, Couillard A, Simar D, et al. Does oxidative stress alter quadriceps endurance in chronic obstructive pulmonary disease? Am J Respir Crit Care Med 2004;169:1022-7.

26. Koechlin C, Maltais F, Saey D, et al. Hypoxaemia enhances peripheral muscle oxidative stress in chronic obstructive pulmonary disease. Thorax 2005;60:834-41.

27. Couillard A, Maltais F, Saey D, et al. Exercise-induced quadriceps oxidative stress and peripheral muscle dysfunction in patients with chronic obstructive pulmonary disease. Am J Respir Crit Care Med 2003;167:1664-9.

28. Allaire J, Maltais F, Doyon JF, et al. Peripheral muscle endurance and the oxidative profile of the quadriceps in patients with COPD. Thorax 2004;59:673-8.

29. Mador MJ, Bozkanat E, Kufel TJ. Quadriceps fatigue after cycle exercise in patients with COPD compared with healthy control subjects. Chest 2003;123:1104-11.

30. Saey D, Côté CH, Mador MJ, et al. Assessment of muscle 
fatigue during exercise in chronic obstructive pulmonary disease. Muscle Nerve 2006;34:62-71.

31. Gan WQ, Man SF, Senthilselvan A, et al. Association between chronic obstructive pulmonary disease and systemic inflammation: a systematic review and a meta-analysis. Thorax 2004;59:574-80.

32. Byun MK, Cho EN, Chang J, et al. Sarcopenia correlates with systemic inflammation in COPD. Int J Chron Obstruct Pulmon Dis 2017;12:669-75.

33. Spruit MA, Gosselink R, Troosters T, et al. Muscle force during an acute exacerbation in hospitalised patients with COPD and its relationship with CXCL8 and IGF-I. Thorax 2003;58:752-6.

34. Marquis K, Debigaré $\mathrm{R}$, Lacasse $\mathrm{Y}$, et al. Midthigh muscle cross-sectional area is a better predictor of mortality than body mass index in patients with chronic obstructive pulmonary disease. Am J Respir Crit Care Med 2002;166:80913.

35. Wagner PD. Possible mechanisms underlying the development of cachexia in COPD. Eur Respir J 2008;31:492-501.

36. Jones SE, Maddocks M, Kon SS, et al. Sarcopenia in COPD: prevalence, clinical correlates and response to pulmonary rehabilitation. Thorax 2015;70:213-8.

37. Jang HC. How to diagnose sarcopenia in Korean older adults? Ann Geriatr Med Res 2018;22:73-9.

38. Limpawattana $P$, Putraveephong $S$, Inthasuwan $P$, et al. Frailty syndrome in ambulatory patients with COPD. Int J Chron Obstruct Pulmon Dis 2017;12:1193-8.

39. Vogelmeier CF, Criner GJ, Martinez FJ, et al. Global Strategy for the diagnosis, management, and prevention of chronic obstructive lung disease 2017 report. GOLD executive summary. Am J Respir Crit Care Med 2017;195:557-82.

40. Suetta C, Magnusson SP, Beyer N, et al. Effect of strength training on muscle function in elderly hospitalized patients. Scand J Med Sci Sports 2007;17:464-72.

41. Levinger I, Goodman C, Hare DL, et al. The reliability of the 1RM strength test for untrained middle-aged individuals. J Sci Med Sport 2009;12:310-6.

42. Binder EF, Yarasheski KE, Steger-May K, et al. Effects of progressive resistance training on body composition in frail older adults: results of a randomized, controlled trial. J Gerontol A Biol Sci Med Sci 2005;60:1425-31.

43. Orr R, Raymond J, Fiatarone Singh M. Efficacy of progressive resistance training on balance performance in older adults: a systematic review of randomized controlled tri- als. Sports Med 2008;38:317-43.

44. Low DC, Walsh GS, Arkesteijn M. Effectiveness of exercise interventions to improve postural control in older adults: a systematic review and meta-analyses of centre of pressure measurements. Sports Med 2017;47:101-12.

45. American College of Sports Medicine. ACSM's guidelines for exercise testing and prescription. 10th ed. Philadelphia, PA: Wolters Kluwer; 2018.

46. Kendrick KR, Baxi SC, Smith RM. Usefulness of the modified 0-10 Borg scale in assessing the degree of dyspnea in patients with COPD and asthma. J Emerg Nurs 2000;26: 216-22.

47. Ries AL, Bauldoff GS, Carlin BW, et al. Pulmonary rehabilitation: Joint ACCP/AACVPR evidence-based clinical practice guidelines. Chest 2007;131:4s-42s.

48. van Gestel AJ, Clarenbach CF, Stöwhas AC, et al. Prevalence and prediction of exercise-induced oxygen desaturation in patients with chronic obstructive pulmonary disease. Respiration 2012;84:353-9.

49. Johannson KA, Vittinghoff E, Lee $K$, et al. Acute exacerbation of idiopathic pulmonary fibrosis associated with air pollution exposure. Eur Respir J 2014;43:1124-31.

50. Ministry of Health and Welfare, The Korean Nutrition Society. Dietary reference intakes for Koreans 2015. Sejong: Ministry of Health and Welfare, The Korean Nutrition Society; 2015.

51. Houston DK, Nicklas BJ, Ding J, et al. Dietary protein intake is associated with lean mass change in older, community-dwelling adults: the Health, Aging, and Body Composition (Health ABC) Study. Am J Clin Nutr 2008;87:150-5.

52. Bauer JM, Verlaan S, Bautmans I, et al. Effects of a vitamin $D$ and leucine-enriched whey protein nutritional supplement on measures of sarcopenia in older adults, the PROVIDE study: a randomized, double-blind, placebo-controlled trial. J Am Med Dir Assoc 2015;16:740-7.

53. Verreijen AM, Verlaan S, Engberink MF, et al. A high whey protein-, leucine-, and vitamin D-enriched supplement preserves muscle mass during intentional weight loss in obese older adults: a double-blind randomized controlled trial. Am J Clin Nutr 2015;101:279-86.

54. Tieland M, Dirks ML, van der Zwaluw N, et al. Protein supplementation increases muscle mass gain during prolonged resistance-type exercise training in frail elderly people: a randomized, double-blind, placebo-controlled trial. J Am Med Dir Assoc 2012;13:713-9. 
55. Ferreira IM, Brooks D, White J, et al. Nutritional supplementation for stable chronic obstructive pulmonary disease. Cochrane Database Syst Rev 2012;12:Cd000998.

56. Bauer J, Biolo G, Cederholm T, et al. Evidence-based recommendations for optimal dietary protein intake in older people: a position paper from the PROT-AGE Study Group. J Am Med Dir Assoc 2013;14:542-59.

57. Boland R. Role of vitamin D in skeletal muscle function. Endocr Rev 1986;7:434-48.

58. Kuchuk NO, Pluijm SM, van Schoor NM, et al. Relationships of serum 25-hydroxyvitamin D to bone mineral density and serum parathyroid hormone and markers of bone turnover in older persons. J Clin Endocrinol Metab 2009; 94:1244-50.

59. Wilson GJ, Wilson JM, Manninen AH. Effects of beta-hydroxy-beta-methylbutyrate $(\mathrm{HMB})$ on exercise performance and body composition across varying levels of age, sex, and training experience: A review. Nutr Metab (Lond) 2008; 5:1.

60. Wu H, Xia Y, Jiang J, et al. Effect of beta-hydroxy-beta-methylbutyrate supplementation on muscle loss in older adults: a systematic review and meta-analysis. Arch Gerontol Geriatr 2015;61:168-75.

61. Molfino A, Gioia G, Rossi Fanelli F, et al. Beta-hydroxy-beta-methylbutyrate supplementation in health and disease: a systematic review of randomized trials. Amino Acids 2013;45:1273-92.

62. Dalton JT, Taylor RP, Mohler ML, et al. Selective androgen receptor modulators for the prevention and treatment of muscle wasting associated with cancer. Curr Opin Support Palliat Care 2013;7:345-51.

63. Kolosova NG, Vitovtov AO, Stefanova NA. Metformin reduces the signs of sarcopenia in old OXYS rats. Adv Gerontol 2016;6:70-4. 